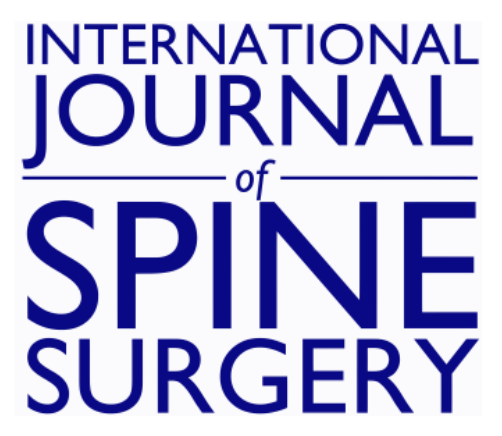

\title{
Segmental Motion of Cervical Arthroplasty Leads to Decreased Adjacent-Level Degeneration: Analysis of the 7-Year Postoperative Results of a Multicenter Randomized Controlled Trial
}

Jeffrey M. Spivak, Jack E. Zigler, Travis Philipp, Michael Janssen, Bruce Darden and Kris Radcliff

Int J Spine Surg published online 17 February 2022

http://ijssurgery.com/content/early/2022/02/17/8187

This information is current as of April 26, 2023.

Email Alerts Receive free email-alerts when new articles cite this article. Sign up at:

http://ijssurgery.com/alerts

The International Journal of Spine Surgery

2397 Waterbury Circle, Suite 1,

Aurora, IL 60504, Phone: +1-630-375-1432 


\title{
Segmental Motion of Cervical Arthroplasty Leads to Decreased Adjacent-Level Degeneration: Analysis of the 7-Year Postoperative Results of a Multicenter Randomized Controlled Trial
}

\author{
JEFFREY M. SPIVAK ${ }^{1}$; JACK E. ZIGLER, MD²; TRAVIS PHILIPP, MD ${ }^{3}$; MICHAEL JANSSEN, DO ${ }^{4}$; BRUCE DARDEN, \\ $\mathrm{MD}^{5}$; AND KRIS RADCLIFF, MD ${ }^{6}$ \\ ${ }^{I}$ NYU Langone Orthopedic Hospital, New York, NY, USA; ${ }^{2}$ Texas Back Institute, Plano, TX, USA $;{ }^{3}$ Oregon Health and Science University, Sam Jackson Hall, Portland, \\ OR, USA $;{ }^{4}$ Center for Spinal Disorders, Center for Spinal Disorders, Thornton, CO, USA; ${ }^{5}$ Ortho Carolina Spine Center, Charlotte, NC, USA; ${ }^{6}$ Rothman Orthopedics, \\ Philadelphia, PA, USA
}

\begin{abstract}
Background: Cervical artificial disc replacement (C-ADR) has become a common and accepted surgical treatment for many patients with cervical disc degeneration/herniation and radiculopathy who have failed nonoperative treatment. Midterm follow-up studies of the original investigational device exemption trials comparing C-ADR to traditional anterior cervical discectomy and fusion (ACDF) have revealed C-ADR patients have less adjacent-level disease and fewer reoperations at 5 to 7 years. The purpose of this study was to examine the relationship of radiographic adjacent-level disease (R-ALD) with the amount of index-level segmental range of motion (ROM) in C-ADR patients using the long-term follow-up data from the ProDisc-C investigational device exemption trial.

Methods: This was a post hoc analysis of a 1:1 randomized controlled trial. The initial previously described Food and Drug Administration-approved 2-year study was extended, and consenting patients in the original study were followed at annual intervals up to 7 years. Logistic regression was used to assess any progression in adjacent-level disease (ALD). Ordinal logistic regression was also used to assess the relationship between any progressive R-ALD and final flexion extension (F/E) ROM in C-ADR patients. Spearman's rank-order correlation was used when R-ALD was kept as an ordinal variable to assess the same relationship.

Results: At the last follow-up visit, the rate of progressive R-ALD was significantly higher in ACDF patients than in CADR patients. When C-ADR patients were divided into 3 groups based on final F/E ROM, those with $0^{\circ}$ to $3^{\circ}(n=19), 4^{\circ}$ to $6^{\circ}$ $(n=15)$, and $7^{\circ}(n=42)$ of segmental motion at the index procedure level, the rate of progressive R-ALD trended significantly with final $\operatorname{ROM}(P=0.01)$.

Conclusions: C-ADR leads to a significant decrease in R-ALD compared to ACDF. The difference in R-ALD is related to the preservation of motion at the index level and resultant preservation of kinematics and forces across the adjacent disc space.

Level of Evidence: 4.
\end{abstract}

Total Disc Replacement

Keywords: cervical arthroplasty, adjacent segment degeneration, disc replacement

\section{INTRODUCTION}

Cervical artificial disc replacement (C-ADR) has become a common and accepted surgical treatment for many patients with cervical disc degeneration/herniation with radiculopathy who have failed nonoperative treatment. ${ }^{1-3}$ Rather than stabilizing the decompressed disc space with a rigid fusion, in C-ADR, the decompression is followed by stabilization via placement of a mobile bearing device, which allows some degree of controlled segmental motion to continue.

High rates of both radiographic and clinically significant adjacent-level degeneration (R-ALD and C-ALD) have been reported following anterior cervical discectomy and fusion (ACDF). ${ }^{4-8}$ This may be due to, at least in part, the increased stresses seen with cervical motion at the levels adjacent to a disc made rigid by fusion ${ }^{5,6,9}$ One theoretical advantage of C-ADR over ACDF is that by maintaining segmental cervical motion at the treated level, less stress will be put on the adjacent levels, and the rate of R-ALD, and ultimately C-ALD, will be lessened. ${ }^{10-14}$

Initial 2-year results of C-ADR trials revealed the noninferiority of cervical disc replacement to ACDF. ${ }^{15,16}$ However, the theoretical benefits of preserving motion with cervical disc replacement were not 
realized during this short time window. Midterm follow-up studies revealed more divergence in results in terms of adjacent-level disease (ALD) and reoperation rates with C-ADR patients having less ALD and fewer reoperations at 5-7 years. ${ }^{17-23} \mathrm{C}$-ADR clinical trials randomized with fusion controls have been ongoing, allowing for analysis of longer-term outcomes of these patients.

One systematic review pooled the results from 3 trials describing clinically significant adjacent segment degeneration and found that the rate of ASD was not significantly different between ACDF and C-ADR. While they did find that the overall rate of reoperation for C-ADR was lower than for ACDF, when looking at reoperation specifically for ASD they could no longer find a difference. ${ }^{24} \mathrm{~A}$ more recent systematic review and meta-analysis of randomized controlled trials comparing C-ADR with ACDF was performed. It included 11 trials with a total of 3505 patients and at least 5 years of follow-up. The authors concluded that C-ADR patients had fewer total secondary surgeries, fewer secondary surgeries at the index and adjacent levels, and fewer cases of symptomatic ASD. ${ }^{3}$ This finding contrasts with a retrospective review of a Swedish database that found C-ADR had similar secondary surgery rates at the adjacent levels but a significantly higher secondary surgery rate at the index level. It is important to note that the artificial disc predominantly used in this study has not

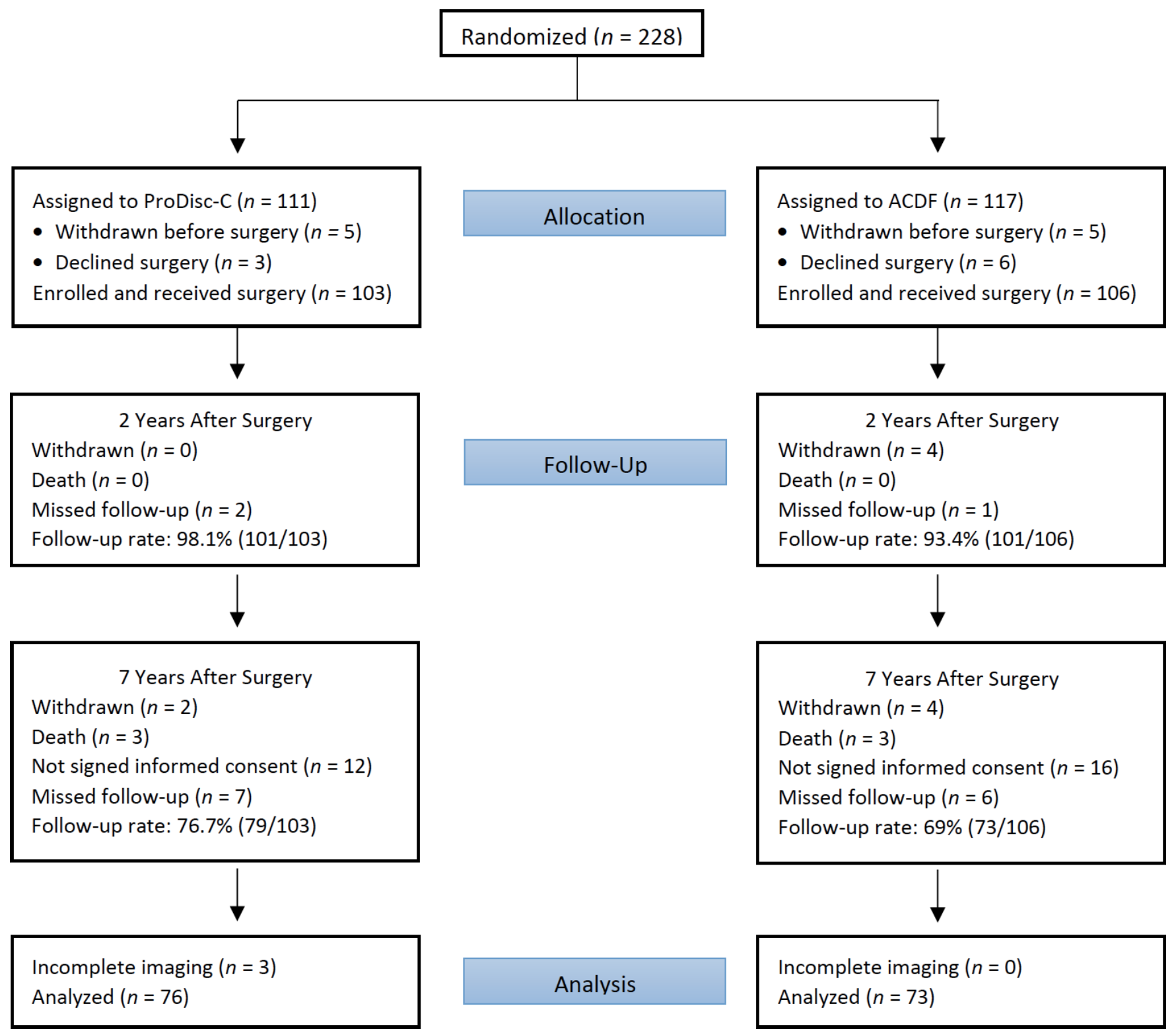

Figure 1. Randomization and follow-up flow chart. "Withdrew" indicates that the patient signed the informed consent but later withdrew from the study. "Missed follow-up" means the patient was lost to follow-up. ACDF, anterior cervical discectomy and fusion. 

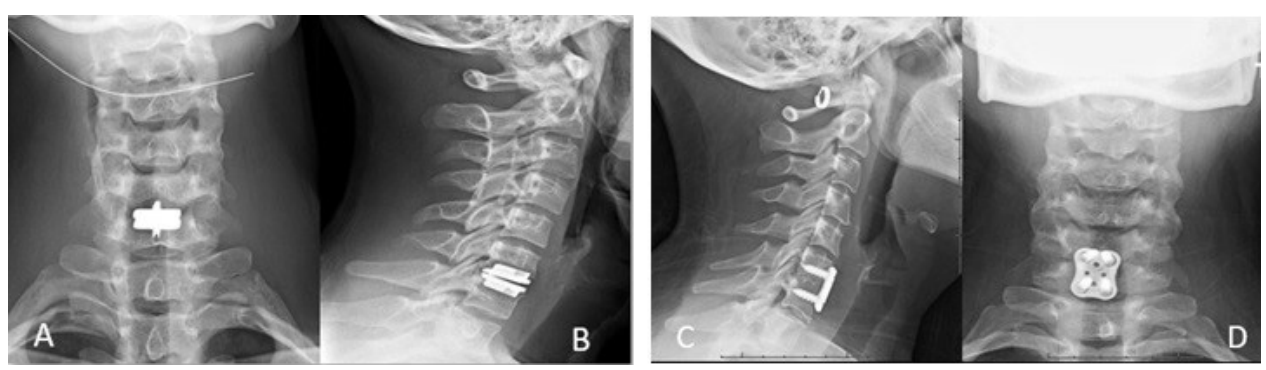

Figure 2. Example of C6-7 cervical disc replacement vs anterior cervical discectomy and fusion.

been approved by the Food and Drug Administration for use in the United States. ${ }^{25}$

The purpose of this study was to review the original randomized ProDisc-C investigational device exemption study database with follow-up to 7 years to evaluate the rates of R-ALD for patients treated with either ProDisc-C or ACDF and to examine the relationship between R-ALD and the amount of index-level segmental range of motion (ROM) in C-ADR patients at long-term follow-up. The author's hypothesis was that improved, index level, segmental ROM in C-ADR patients will correlate to lower rates of adjacent-level degeneration.

\section{MATERIALS AND METHODS}

\section{Study Design}

The study design for the randomized controlled trial comparing results of ProDisc-C vs ACDF with follow-up through 2 and 5 years has been described previously. ${ }^{16,26}$ As part of a Food and Drug Administration-regulated post approval study, the 2-year study was extended and consenting patients in the original study were followed at annual intervals up to 7 years (Figure 1). Institutional review board approval was obtained for the initial and postapproval studies (clinical trial identification number NCT00291018).

Patients were randomized and remained blinded to their treatment assignment until after surgery. Patients were evaluated preoperatively at regular intervals up to 2 years and then annually up to 7 years. A last-observationcarried-forward design was used to include patients in this study, which was a post hoc analysis with a minimum final follow-up of 5 years. The primary patient inclusion criteria included symptomatic cervical disc disease causing intractable, debilitating radiculopathy from 1 vertebral motion segment between $\mathrm{C} 3$ and $\mathrm{C} 7$, unresponsive to nonoperative treatment for at least 6 weeks, and an Neck Disability Index score of $15 / 50(30 \%)$ or greater. All patients were randomized $1: 1$ to receive 1 of the 2 surgical treatment options for stabilization following anterior cervical discectomy and decompression. The study group received the
ProDisc-C C-ADR implant. For the control group, a standard fusion technique was used with an allograft structural bone graft and anterior cervical plate fixation.

All radiographic analysis was based on a digitized radiographic review by radiologists at an independent facility (Medical Metrics, Inc, Houston, TX). ALD was assessed at the levels immediately adjacent to the treated index level based on neutral lateral standing radiographs obtained prior to surgery (C-ADR or ACDF) and at each postsurgery assessment. The grade of any presurgery ALD was assessed as well as the grade of ALD at final follow-up for both the disc above and below the treated level. Figure 2 demonstrates illustrative pre- and postoperative radiographs of C-ADR and ACDF patients.

To characterize ALD, Medical Metrics utilized the Kellgren-Lawrence classification for grading disc degeneration originally described in $1957 .{ }^{27}$ In reading the films, an atlas of images defined by Kellgren et al and subsequently updated was referenced. ${ }^{27,28}$ Medical Metrics supplemented the atlas with instructions and images. Disc degeneration was assessed based on disc height loss, osteophyte formation, and endplate sclerosis and classified as defined in Figure 3. Two radiologists read each film and, if required, a third radiologist participated to resolve any grading discrepancies. Progressive ALD was defined as any grade progression of either or both adjacent levels. Severe progressive ALD was defined as a patient having 1 or both adjacent discs grade 0 or 1 preoperatively with progression to grade 3 or 4 at final follow-up.

In addition, Medical Metrics' Quantitative Motion Analysis software, a previously validated software system, was utilized to provide quantitative measures of flexion extension (F/E) ROM for the C-ADR segment at final follow-up. Patients were grouped into those with segmental motion of $0^{\circ}$ to $3^{\circ}, 4^{\circ}$ to $6^{\circ}$, and $7^{\circ}+$.

\section{Statistical Analysis}

This analysis provides a comprehensive assessment of the results through 7 years for the ongoing multicenter randomized controlled trial. Patients were included in the 


\begin{tabular}{|c|c|}
\hline 0 -None & No degenerative changes \\
\hline 1 -Doubtful & Minimal anterior osteophytosis \\
\hline 2-Minimal & $\begin{array}{l}\text { Definite anterior osteophytosis; possible narrowing of disk space and some } \\
\text { endplate sclerosis }\end{array}$ \\
\hline 3-Moderate & $\begin{array}{l}\text { Moderate narrowing of disk space; definite sclerosis of vertebral plates and } \\
\text { osteophytosis }\end{array}$ \\
\hline 4-Severe & $\begin{array}{l}\text { Severe narrowing of disk space; sclerosis of vertebral plates; multiple large } \\
\text { osteophytes }\end{array}$ \\
\hline 5 - Indeterminate & A reliable determination cannot be made from the available images. \\
\hline 6-Unable to Assess & The relevant images are missing, unavailable, or inadequate. \\
\hline
\end{tabular}

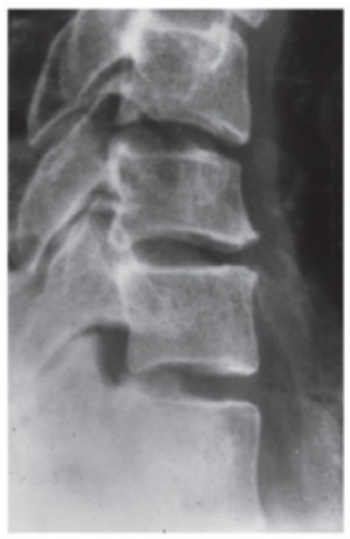

Doubtful

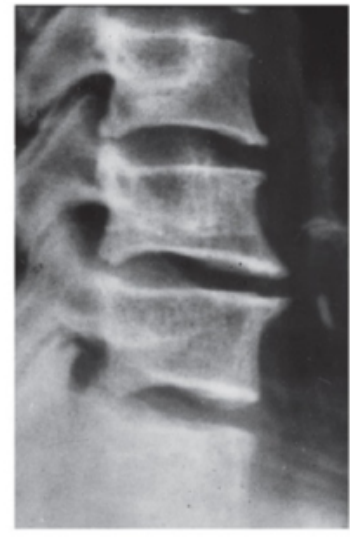

Minimal

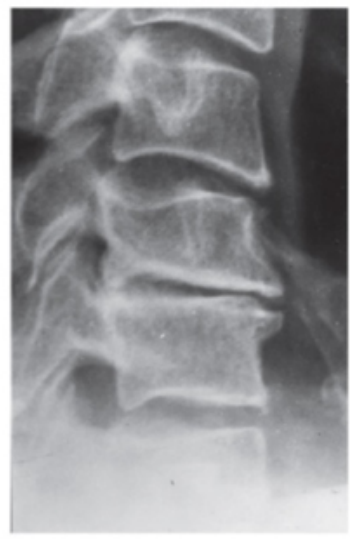

Moderate

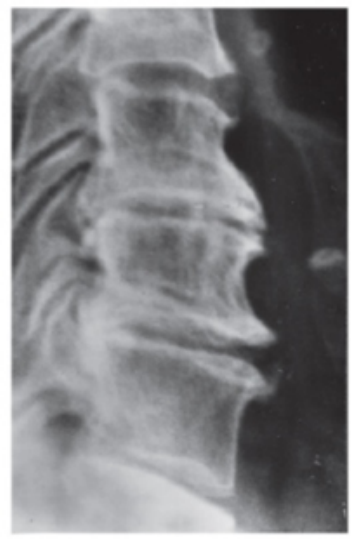

Severe

Figure 3. Example of Kellgren-Lawrence classification for grading disc degeneration originally described in 1957.

analysis who had follow-up results with corresponding radiographic assessments at a minimum of 5 years postoperatively. Missing 7-year radiographic assessments of adjacent-level degeneration were imputed using the 5- or 6-year assessments in a last observation carried forward fashion. Whenever the adjacent-level degeneration was imputed, the index ROM was also carried forward. $\triangle \mathrm{ALD}$ was defined as the change at the final visit in grade of adjacent-level degeneration from the preoperative baseline assessment. The largest progression among the 2 adjacent levels was the one assigned to the patient. Ordinal logistic regression was applied to assess preoperative differences in the frequency of patients across the various grades of adjacent-level degeneration. Logistic regression with any progression as the dependent variable and treatment and baseline degeneration as independent variables were used to assess any progression in ALD. Ordinal logistic regression was also used to assess the relationship between any progressive R-ALD and final F/E ROM in C-ADR patients. Spearman's rank-order correlation was used when R-ALD was kept as an ordinal variable to assess the same relationship. SAS Statistical Software Version 9.3 (SAS Institute, Cary, NC) and alpha of 0.05 were used for all statistical analyses.

\section{RESULTS}

\section{Patient Characteristics}

From August 2003 to October 2004, 228 patients were enrolled, and 207 patients were randomized and treated (103 C-ADR and 106 ACDF). Baseline demographic details on these 2 groups have previously been published. ${ }^{19}$ Final follow-up with radiographic exams was available for 149 patients (76 C-ADR $=74 \%$ and $73 \mathrm{ACDF}=69 \%$ ). Utilizing the last observation carried forward design (minimum of 5 years follow-up), the majority of these patients, 133 (89\%), at final follow-up had full 7-year data, with 10 patients having final follow-up at 5 years and 6 patients at 6 years. Overall patient demographics showed no statistically significant differences between the treatment groups.

\section{Radiographic Adjacent-Level Degeneration-ACDF vs C-ADR}

Prior to surgery, the rate of no or minimal evidence of R-ALD was comparable between groups $(85 \%$ C-ADR and $76 \%$ ACDF with $P=0.05)$. As shown in Figure 4, at the last follow-up visit, the rate of progressive R-ALD was significantly higher in ACDF patients 


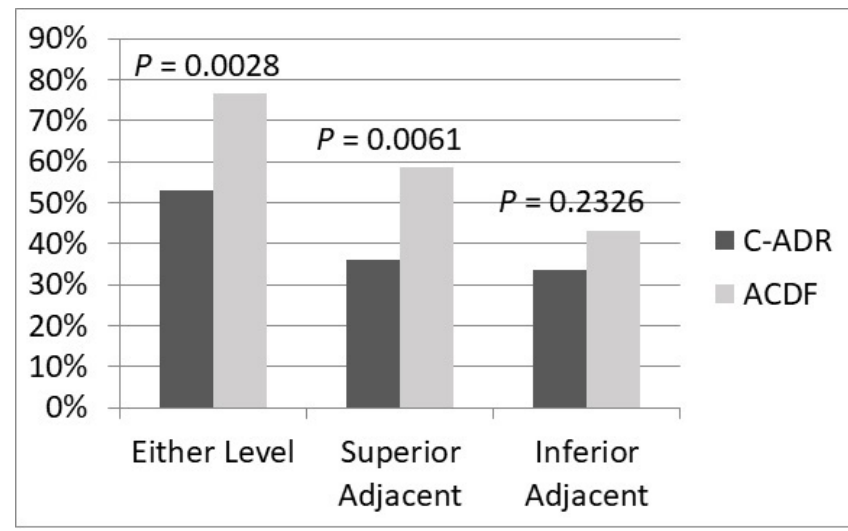

Figure 4. Rate of progressive adjacent- level degeneration between anterior cervical discectomy and fusion (ACDF) and cervical artificial disc replacement (C-ADR).

than in C-ADR patients (77\% vs $53 \%, P=0.0028)$. When the superior and inferior adjacent levels are analyzed separately, only the superior adjacent level had a significantly different rate of progressive R-ALD in the ACDF and C-ADR patients (59\% vs 36\%, $P=0.0061)$.

\section{Radiographic Adjacent-Level \\ Degeneration-C-ADR and Final F/E ROM}

C-ADR patients were divided into 3 groups based on final F/E ROM: those with $0^{\circ}$ to $3^{\circ}(n=19), 4^{\circ}$ to $6^{\circ}$ $(n=15)$, and $7^{\circ}+$ degrees $(n=42)$ of segmental motion at the index procedure level. Figure 5 displays the rate of progressive R-ALD by final C-ADR ROM group and includes the ACDF patients, which represents a $0^{\circ}$ ROM group. The rate of progressive R-ALD trended significantly with final ROM $(P=0.01)$.

Progressive R-ALD was also examined for number of grades of progression (0-4) within each ROM group (Figure 6). When analyzed in this fashion, the rate of

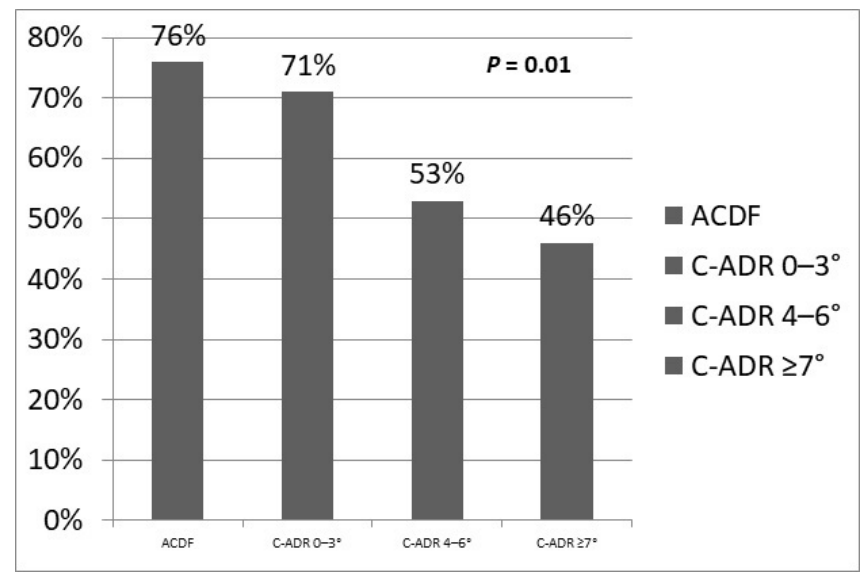

Figure 5. Rate of progressive radiographic adjacent-level disease by final cervical artificial disc replacement (C-ADR) range of motion (ROM) group (includes the anterior cervical discectomy and fusion [ACDF] patients, which represents a $0^{\circ} \mathrm{ROM}$ group).

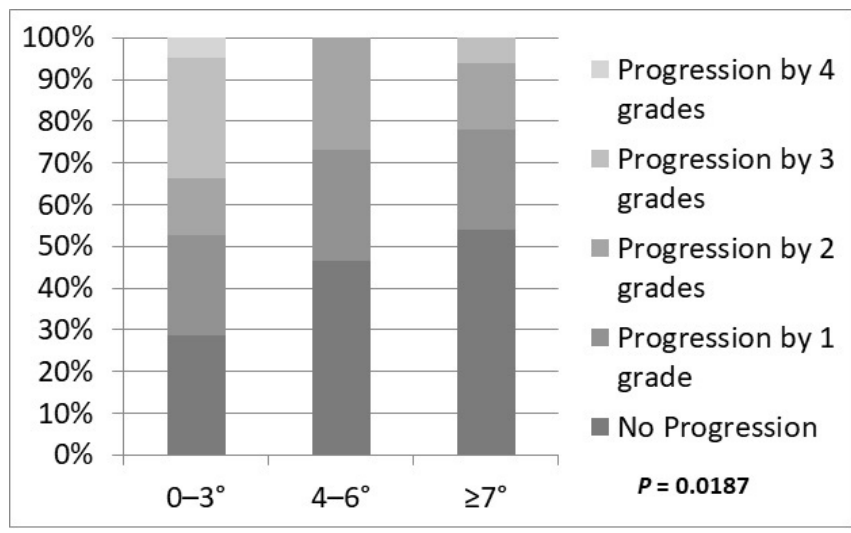

Figure 6. Magnitude of progression of adjacent-level disease by range of motion group.

progressive degeneration is found to vary inversely with final F/E ROM, reaching statistical significance $(P=0.0187)$. This is because more advanced amounts of progressive degeneration ( $2-4$ grades) were seen in the minimal motion group. When severe progressive R-ALD was examined (grade $0-1$ preoperatively, progressing to grade 3-4 postoperatively), a significant difference was seen in the 3 groups as well, with more severe progressive R-ALD in the $0^{\circ}$ to $3^{\circ}$-group than the other 2 groups $(P=0.0013)$ (Figure 7).

\section{DISCUSSION}

Despite excellent reported outcomes following ACDF, there are concerns regarding adjacent-level breakdown, which is inherent with any fusion procedure. This can result in pain, disability, and reoperation in many of these patients. Five to 10 years following ACDF, reported rates of radiographic ALD range from $25 \%$ to $73 \%$. $^{7,29-31}$ Hilibrand reported that $2.9 \%$ of patients per year develop symptomatic ALD following

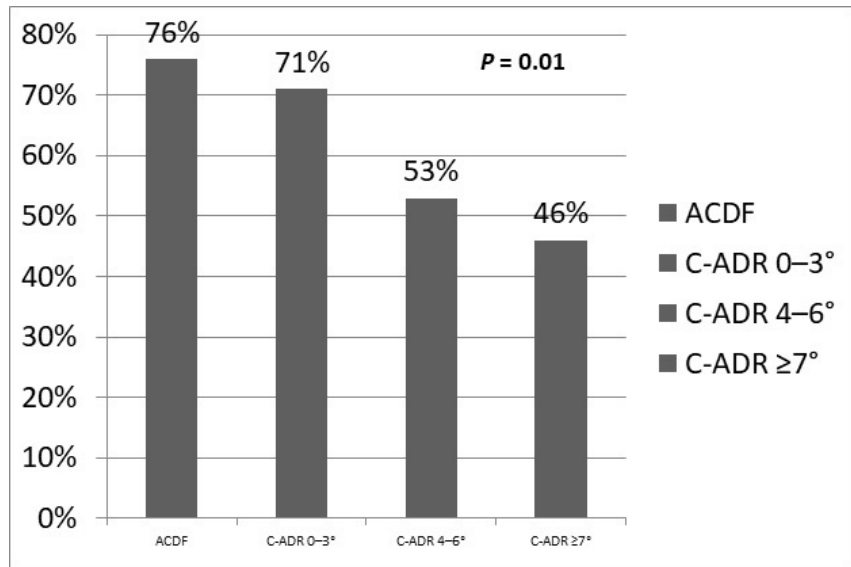

Figure 7. Rate of severe progression of adjacent-level disease by range of motion group. 
single-level ACDF. Two-thirds of these patients required an additional operation. ${ }^{13}$

Authors have postulated that the now rigid, fused motion segment following ACDF results in more stress with spinal movement transferred to the immediately adjacent disc spaces. This has been supported by biomechanical studies showing that there are higher intradiscal pressures as well as increased segmental motion in levels adjacent to a cervical fusion. ${ }^{6,32,33}$ Eck et al found significant increased intradiscal pressures surrounding C5-6 fusion stabilization of $73.2 \%$ at $\mathrm{C} 4-5 \%$ and $45.3 \%$ at C6-7 in a cadaveric model. ${ }^{32}$ Dmitriev et al studied adjacent-level intradiscal pressure following simulated ACDF and total disc replacement. ${ }^{33}$ They found that, as compared to the intact condition, intradiscal pressures were significantly increased at the adjacent segments following simulated fusion constructs with and without plating while intradiscal pressures were similar to intact specimens following disc replacement. Chang et al compared cervical fusion to C-ADR in a cadaveric model and found no significant difference in intradiscal pressure at the proximal and distal levels following disc replacement. ${ }^{12}$ The difference in pressure with F/E was significantly different at the rostral adjacent level in the fusion group while the caudal level did not have significant pressure changes. Elsawaf et al assessed the effect of ACDF on motion and dynamic stress on adjacent levels in vivo. ${ }^{5}$ They found that in the $20 \%$ of patients that developed symptomatic ALD following ACDF, the sagittal ROM of levels adjacent to fusion was increased. The above studies lend support to 1 of the purported benefits of C-ADR over ACDF; preserved motion at the index procedure level with $\mathrm{C}$-ADR will decrease rates of ASD and secondary surgery.

Early results of multiple randomized controlled trials comparing C-ADR to cervical fusion did not support this hypothesis. Botelho et al looked at pooled results of randomized controlled trials comparing C-ADR to ACDF with 24 months of follow-up. ${ }^{34}$ The authors concluded that adjacent-level degeneration had not been adequately studied and that there was no clinical evidence of reduction in adjacent-level degeneration with the use of cervical arthroplasty. However, subsequent studies following long-term outcomes of C-ADR vs ACDF patients have consistently found lower rates of reoperation in the C-ADR cohorts. ${ }^{20,22,23,35,36}$ Burkus et al reported 7-year follow-up from the Prestige clinical trial and found a $4.6 \%$ rate of surgery at adjacent levels in the C-ADR cohort vs a $11.9 \%$ rate in the fusion cohort. Zigler et al previously reported the 5-year outcomes of the Pro-Disc trial and found a cumulative reoperation rate of $2.9 \%$ in the $\mathrm{C}$-ADR cohort and $11.3 \%$ in the ACDF cohort $P=0.0292 .{ }^{18}$ More recently, Janssen et al reported an $18 \%$ reoperation rate in the ACDF cohort vs a $7 \%$ reoperation rate in the $\mathrm{C}$-ADR cohort $^{36}$ at 7 years postop. Lavelle et al reported 10-year outcomes of the BRYAN disc investigational device exemption trial, finding 9.7\% C-ADR patients had an adjacent-level surgery while $15.8 \%$ of the ACDF patient did. This finding did not reach statistical significance. ${ }^{37}$ Wang et al recently pooled long-term results from randomized, controlled trials comparing ACDF to C-ADR. ${ }^{3}$ These authors found that after 5 years of follow-up C-ADR had a higher rate of clinical success. The incidence of ASD was significantly lower in CDA $(\mathrm{OR}=0.46, P<$ 0.00001 ), and CDA had fewer total secondary surgeries $(\mathrm{OR}=0.5, P=0.01)$ and secondary surgery at the adjacent level $(\mathrm{OR}=0.37, P<0.00001)$.

The results of this study demonstrated a higher overall rate of radiographic ALD in ACDF patients when compared to C-ADR patients $(77 \%$ vs $53 \%, P=$ $0.0020)$. Analyzing the superior and inferior adjacent levels separately, only the superior adjacent level had a significantly different rate of progressive radiographic ALD between the ACDF and C-ADR patients (59\% vs $36 \%, P=0.0059$ ), which aligns with the biomechanical results of Park and Chang where the intradiscal pressure adjacent to a fusion rostrally and not caudally was significantly increased. ${ }^{6,38}$ When further broken down into 3 groups by $\mathrm{ROM}$ at the index procedure level into $0^{\circ}$ to $3^{\circ}, 4^{\circ}$ to $6^{\circ}$, and $7^{\circ}+$, the rate of progressive radiographic ALD was inversely proportional $(P=0.01)$ (Figure 5). Figure 6 shows the magnitude of progression of R-ALD within each index ROM group. The rate of progressive degeneration is found to vary inversely with final sagittal ROM $(P=0.0187)$. These results support the concept that preserving motion at the index procedure level with C-ADR is associated with a proportional reduction in the rate of progressive R-ALD. The difference in R-ALD among C-ADR patients based on ROM at the index level supports the idea that meticulous technique to maintain motion of the C-ADR has important clinical consequences and maximizes the benefits of C-ADR over ACDF.

\section{Strengths/Limitations}

To the authors knowledge, this is the first study to report R-ASD as correlated to sagittal ROM at the index procedure level for C-ADR patients. The findings are based on post hoc analysis of prospectively collected data from a multicenter randomized controlled trial with long-term follow-up. Limitations of the study 
include the $29 \%$ of patients with missing data or loss to follow-up before 5 years of follow-up were completed. The radiographic review was not blinded to treatment, as the difference in a plated fusion and a C-ADR are obvious (but was made by third-party radiologists). Also, this study looked specifically at R-ALD; the clinical consequences are not included. However, a previous publication based on the outcomes of the same cohort of Pro-Disc trial patients with 7 years follow-up found that the incidence of secondary surgery was significantly higher in the ACDF group compared to the C-ADR group, 19 patients vs 7 procedures $(P=0.02) .{ }^{19}$

\section{CONCLUSIONS}

C-ADR leads to a significant decrease in R-ALD compared to ACDF. The difference in R-ALD is related to the preservation of motion at the index level and resultant preservation of kinematics and forces across the adjacent disc space.

\section{ACKNOWLEDGMENTS}

The authors acknowledge Thierry Bernard, MS, for the statistical analysis.

\section{REFERENCES}

1. Upadhyaya CD, Jau-Ching W, Trost G, et al. Analysis of the three United States food and drug administration investigational device exemption cervical arthroplasty trials. J Neurosurg Spine. 2012;16(3):216-228. doi:10.3171/2011.6.SPINE10623

2. Mehren C, Heider F, Siepe CJ, et al. Clinical and radiological outcome at 10 years of follow-up after total cervical disc replacement. Eur Spine J. 2017;26(9):2441-2449. doi:10.1007/s00586017-5204-6

3. Wang Q-L, Zhi-Ming T, Hu P, et al. Long-term results comparing cervical disc arthroplasty to anterior cervical discectomy and fusion: a systematic review and metaa-analysis of randomized controlled trials. Orthop Surg. 2020;12(1):16-30. doi:10.1111/ os. 12585

4. Hilibrand AS, Carlson GD, Palumbo MA, Jones PK, Bohlman HH. Radiculopathy and myelopathy at segments adjacent to the site of a previous anterior cervical arthrodesis. J Bone Joint Surg Am. 1999;81(4):519-528. doi:10.2106/00004623-19990400000009

5. Elsawaf A, Mastronardi L, Roperto R, Bozzao A, Caroli M, Ferrante L. Effect of cervical dynamics on adjacent segment degeneration after anterior cervical fusion with cages. Neurosurg Rev. 2009;32(2):215-224. doi:10.1007/s10143-008-0164-2

6. Park D-H, Ramakrishnan P, Cho T-H, et al. Effect of lower two-level anterior cervical fusion on the superior adjacent level. $J$ Neurosurg Spine. 2007;7(3):336-340. doi:10.3171/SPI-07/09/336

7. Sugawara T, Itoh Y, Hirano Y, Higashiyama N, Mizoi K. Long term outcome and adjacent disc degeneration after anterior cervical discectomy and fusion with titanium cylindrical cages. Acta Neurochir. 2009;151(4):303-309. doi:10.1007/s00701-009-0217-5
8. Herkowitz HN, Kurz LT, Overholt DP. Surgical management of cervical soft disc herniation. A comparison between the anterior and posterior approach. Spine. 1990;15(10):1026-1030. doi:10.1097/00007632-199015100-00009

9. Eck JC, Humphreys SC, Lim T-H, et al. Biomechanical study on the effect of cervical spine fusion on adjacent-level intradiscal pressure and segmental motion. Spine. 2002;27(22):2431-2434. doi:10.1097/00007632-200211150-00003

10. Luo J, Gong M, Huang S, Yu T, Zou X. Incidence of adjacent segment degeneration in cervical disc arthroplasty versus anterior cervical decompression and fusion meta-analysis of prospective studies. Arch Orthop Trauma Surg. 2015;135(2):155-160. doi:10.1007/s00402-014-2125-2

11. Kim BJ, Kim SH, Lee SH, Sung-KonH, Kim SD, Lim DJ. Segmental motion of the cervical spine after total disc replacement using ActivC versus discectomy and fusion using stand-alone cage. World Neurosurg. 2019;126:e1228-e1234. doi:10.1016/j. wneu.2019.02.233

12. Chang UK, Kim DH, Lee MC, Willenberg R, Kim SH, Lim J. Changes in adjacent-level disc pressure and facet joint force after cervical arthroplasty compared with cervical discectomy and fusion. J Neurosurg Spine. 2007;7(1):33-39. doi:10.3171/SPI-07/07/033

13. Verma K, Gandhi SD, Maltenfort M, et al. Rate of adjacent segment disease in cervical disc arthroplasty versus single-level fusion: meta-analysis of prospective studies. Spine. 2013;38(26):2253-2257. doi:10.1097/BRS.0000000000000052

14. Laxer EB, Darden BV, Murrey DB, et al. Adjacent segment disc pressures following two-level cervical disc replacement versus simulated anterior cervical fusion. Stud Health Technol Inform. 2006; 123:488-492.

15. Bertagnoli R, Yue JJ, Pfeiffer F, et al. Early results after ProDisc-C cervical disc replacement. J Neurosurg Spine. 2005;2(4):403-410. doi:10.3171/spi.2005.2.4.0403

16. Murrey D, Janssen M, Delamarter R, et al. Results of the prospective, randomized, controlled multicenter Food and Drug Administration investigational device exemption study of the ProDisc-C total disc replacement versus anterior discectomy and fusion for the treatment of 1-level symptomatic cervical disc disease. Spine J. 2009;9(4):275-286. doi:10.1016/j.spinee.2008.05.006

17. Hou Y, Nie L, Pan X, et al. Effectiveness and safety of Mobi-C for treatment of single-level cervical disc spondylosis: a randomised control trial with a minimum of five years of follow-up. Bone Joint J. 2016;98-B(6):829-833. doi:10.1302/0301620X.98B6.36381

18. Zigler JE, Delamarter R, Murrey D, Spivak J, Janssen M. ProDisc-C and anterior cervical discectomy and fusion as surgical treatment for single-level cervical symptomatic degenerative disc disease: five-year results of a Food and Drug Administration study. Spine. 2013;38(3):203-209. doi:10.1097/BRS.0b013e318278eb38

19. Janssen ME, Zigler JE, Spivak JM, Delamarter RB, Darden BV, Kopjar B. ProDisc-C total disc replacement versus anterior cervical discectomy and fusion for single-level symptomatic cervical disc disease. J Bone Joint Surg Am. 2015;97(21):1738-1747. doi:10.2106/JBJS.N.01186

20. Delamarter RB, Zigler J. Five-year reoperation rates, cervical total disc replacement versus fusion, results of a prospective randomized clinical trial. Spine. 2013;38(9):711-717. doi:10.1097/ BRS.0b013e3182797592

21. Vaccaro A, Beutler W, Peppelman W, et al. Long-term clinical experience with selectively constrained SECURE-C cervical artificial disc for 1-level cervical disc disease: results from 
seven-tear follow-up of a prospective, randomized, controlled investigational device exemption clinical trial. Int J Spine Surg. 2018;12(3):377-387. doi:10.14444/5044

22. Burkus JK, Traynelis VC, Haid RW, Mummaneni PV. Clinical and radiographic analysis of an artificial cervical disc: 7-year follow-up from the Prestige prospective randomized controlled clinical trial: clinical article. J Neurosurg Spine. 2014;21(4):516-528. doi:10.3171/2014.6.SPINE13996

23. Loumeau TP, Darden BV, Kesman TJ, et al. A RCT comparing 7-year clinical outcomes of one level symptomatic cervical disc disease (SCDD) following ProDisc-C total disc arthroplasty (TDA) versus anterior cervical discectomy and fusion (ACDF). Eur Spine J. 2016;25(7):2263-2270. doi:10.1007/s00586-016-4431-6

24. Ren C, Song Y, Xue Y, Yang X. Mid- to long-term outcomes after cervical disc arthroplasty compared with anterior discectomy and fusion: a systematic review and meta-analysis of randomized controlled trials. Eur Spine J. 2014;23(5):1115-1123. doi:10.1007/ s00586-014-3220-3

25. MacDowall A, Skeppholm M, Lindhagen L, et al. Artificial disc replacement versus fusion in patients with cervical degenerative disc disease with radiculopathy: 5-year outcomes from the National Swedish Spine Register. J Neurosurg Spine. 2019;30(2):159-167. doi:10.3171/2018.7.SPINE18657

26. Zigler JE, Delamarter R, Murrey D, Spivak J, Janssen M. ProDisc-C and anterior cervical discectomy and fusion as surgical treatment for single-level cervical symptomatic degenerative disc disease: five-year results of a Food and Drug Administration study. Spine. 2013;38(3):203-209. doi:10.1097/BRS.0b013e318278eb38

27. Kellgren JL. Atlas of Standard Radiographs: The Epidemiology of Chronic Rheumatism. Vol 2. Oxford: Blackwell; 1963.

28. Croft P. An introduction to the Atlas of standard radiographs of arthritis. Rheumatology. 2005;44(Suppl 4):iv42. doi:10.1093/ rheumatology/kei051

29. Bohlman HH, Emery SE, Goodfellow DB, Jones PK. Robinson anterior cervical discectomy and arthrodesis for cervical radiculopathy. Long-term follow-up of one hundred and twenty-two patients. J Bone Joint Surg Am. 1993;75(9):1298-1307. doi:10.2106/00004623-199309000-00005

30. Goffin J, Geusens E, Vantomme N, et al. Long-term follow-up after interbody fusion of the cervical spine. J Spinal Disord Tech. 2004;17(2):79-85. doi:10.1097/00024720-200404000-00001

31. Azmi H, Schlenk RP. Surgery for postarthrodesis adjacentcervical segment degeneration. Neurosurg Focus. 2003;15(3):E6. doi:10.3171/foc.2003.15.3.6

32. Eck JC, Humphreys SC, Lim T-H, et al. Biomechanical study on the effect of cervical spine fusion on adjacent-level intradiscal pressure and segmental motion. Spine. 2002;27(22):2431-2434. doi:10.1097/00007632-200211150-00003

33. Dmitriev AE, Cunningham BW, Hu N, Sell G, Vigna F, McAfee PC. Adjacent level intradiscal pressure and segmental kinematics following a cervical total disc arthroplasty: an in vitro human cadaveric model. Spine (Phila Pa 1976). 2005;30(10):1165-1172. doi:10.1097/01.brs.0000162441.23824.95
34. Botelho RV, dos S Moraes OJ, Fernandes GA, dos Buscariolli YS, Bernardo WM. A systematic review of randomized trials on the effect of cervical disc arthroplasty on reducing adjacent-level degeneration. Neurosurg Focus. 2010;28(6). doi:10.3171/2010.3. FOCUS1032

35. Ghobrial GM, Lavelle WF, Florman JE, Riew KD, Levi AD. Symptomatic adjacent level disease requiring surgery: analysis of 10-year results from a prospective, randomized, clinical trial comparing cervical disc arthroplasty to anterior cervical fusion. Neurosurgery. 2019;84(2):347-354. doi:10.1093/neuros/nyy118

36. Janssen ME, Zigler JE, Spivak JM, Delamarter RB, Darden BV, Kopjar B. ProDisc-C total disc replacement versus anterior cervical discectomy and fusion for single-level symptomatic cervical disc disease. J Bone Joint Surg Am. 2015;97(21):1738-1747. doi:10.2106/JBJS.N.01186

37. Lavelle WF, Riew KD, Levi AD, Florman JE. Ten-year outcomes of cervical disc replacement with the BRYAN cervical disc: results from a prospective, randomized, controlled clinical trial. Spine. 2019;44(9):601-608. doi:10.1097/BRS.0000000000002907

38. Chang U-K, Kim DH, Lee MC, Willenberg R, Kim S-H, Lim J. Changes in adjacent-level disc pressure and facet joint force after cervical arthroplasty compared with cervical discectomy and fusion. J Neurosurg Spine. 2007;7(1):33-39. doi:10.3171/SPI07/07/033

Funding: Investigational device study was supported by Depuy Synthes Spine, Raynham, MA, and Centinel Spine, West Chester, PA

\section{Declaration of Conflicting Interests:}

Dr. Zigler was a consultant for Synthes; however, he received no compensation for work on this study. For the remaining authors, no conflicts of interest were declared.

Ethics approval: This study was approved by the NYU IRB.

Corresponding Author: Travis Philipp, MD, Oregon Health and Science University, Sam Jackson Hall, Suite 2360, 3181 Sam Jackson Park Road, Portland, OR 97239. Email ; philipp@ohsu.edu

Published 15 February 2022

This manuscript is generously published free of charge by ISASS, the International Society for the Advancement of Spine Surgery. Copyright (C) 2022 ISASS. To see more or order reprints or permissions, see http:// ijssurgery.com. 